

\section{RESUMEN}

La educación musical que se imparte en las escuelas de música debe aspirar a incidir positivamente en el bienestar social de la comunidad en la que están imbricadas. El diseño y desarrollo de proyectos socioeducativos y comunitarios desde los centros de formación musical son actividades con las que, empleando la música como herramienta de mediación, se puede contribuir a paliar las disfunciones sociales del entorno más cercano, así como a generar cohesión social y sentimientos de pertenencia e identidad comunitaria. No obstante, existen ciertas inercias en los modos de hacer y una perpetuación en el tiempo de modelos educativos musicales tradicionales en los que no tienen cabida proyectos innovadores de auténtico compromiso social. En este artículo se analizan los retos y contextos que se presentan a las escuelas de música en este siglo XXI a nivel social y comunitario y el modo de abordarlos a partir de nuevos modelos educativos. La implicación y el compromiso social de las instituciones de formación musical deben originar un cambio en el diseño de actividades buscando la innovación, así como abrir nuevas vías de colaboración con otros agentes sociales e instituciones comunitarias. Para ejemplificar estas sinergias y el modo de proceder a la hora de diseñar un proyecto socioeducativo, se hace una propuesta de diseño de taller socioeducativo como guía para el desarrollo práctico de este tipo de proyectos.

\section{PALABRAS CLAVE}

Educación musical, Educación social, Comunidad, Intervención socioeducativa, Gamificación,

Ámbitos socioeducativos, Taller musical socioeducativo

\section{ABSTRACT}

Music education taught at music schools should aim to have a positive impact on the social well-being of the imbricated communities. The design and development of socio-educational and community projects in music training centres are tasks which, in using music as a tool towards mediation, can contribute to alleviate social dysfunctions in the nearby surroundings as well as to create social cohesion and feelings of community belonging and identity. Nevertheless, there is some inertia in the way things are done and a perpetuation of traditional models of education in music where there is no room for innovative projects with authentic social engagement. This paper will analyse the challenges and contexts that music schools face in the $21 \mathrm{st}$ Century at a social and community level, and how to address them with new educational models. The social commitment and engagement of music training institutions should spark a change in the design of activities through innovation as well as opening new avenues for collaboration with other social and institutional community actors. To illustrate these synergies as well as the design process of a socio-educational project, a proposal design of a socio-educational workshop will be put forth as a practical guide in the development of these programmes.

\section{KEYWORDS}




\title{
LAS ESCUELAS DE MÚSICA Y LOS PROYECTOS MUSICALES SOCIOEDUCATIVOS Y COMUNITARIOS. MODELOS EDUCATIVOS, RETOS Y CONTEXTOS
}

\author{
Margarita Lorenzo de Reizábal
}

\author{
Centro Superior de Música del País Vasco
}

\begin{abstract}
INTRODUCCIÓN
La idea del compromiso social como eje transversal en los diseños curriculares de los centros educativos en España ha permeado en los últimos veinticinco años prácticamente en todas las comunidades educativas. No obstante, el modo en que dicha competencia transversal se ha materializado en los programas y en las actividades didácticas es, a día de hoy, muy dispar y presenta distintos grados de puesta en práctica en el día a día de las aulas. También en el ámbito educativo musical, en instituciones de todos los niveles (enseñanza elemental, profesional, superior, no reglada, pública, privada), se ha visto un esfuerzo, en la última década especialmente, por integrar en los currículos valores transversales como la solidaridad, el bienestar comunitario o el compromiso social.
\end{abstract}

En los foros nacionales e internacionales de educación musical de los últimos años se ha puesto de manifiesto repetidamente por parte de la comunidad de docentes la necesidad de abordar los modos de implementar de manera eficiente y eficaz programas, talleres, actividades y, en general, proyectos con vocación de servicio a la comunidad y a los colectivos más desfavorecidos de la sociedad empleando la música como herramienta de mediación e intervención (según los casos). Permitir que la música vehicule o forme parte de procesos de reinserción social a nivel local es un ejemplo recurrente citado en estos foros en los que, además, se propone que los proyectos se generen en las instituciones educativas musicales en respuesta a las demandas sociales del entorno como forma de servicio a la comunidad y un modo de revertir a la sociedad en la que están imbricadas parte de su activo.
Los proyectos musicales de tipo comunitario -sin connotaciones terapéuticas o de intervenciónson otro de los grandes pilares transversales en los que la educación musical y los centros de música de todos los niveles pueden incidir de manera directa y específica, propiciando una mayor cohesión social y dinamismo cultural en un contexto social próximo, conocido y abarcable. Resulta especialmente llamativo observar que la mayoría de los proyectos musicales socio-comunitarios tienen su origen fuera del ámbito educativo y que estos proyectos se sostienen sin soporte, ayuda o asesoramiento de las instituciones musicales cercanas del entorno. Es como si los músicos que se forman en estas instituciones, los docentes y, en general, toda la comunidad educativa cultivase la música intramuros, pero no permease extramuros. Parece, en buena lógica, que las escuelas de música debieran ser el motor que moviera la cultura musical de una comunidad, que contribuyese al bienestar social de dicha comunidad y a sus sectores más desfavorecidos mediante proyectos socioeducativos y que pusiese su capital humano y sus recursos al servicio de las necesidades del entorno. Sin embargo, lamentablemente, el panorama real es bien distinto. Es cierto que existen iniciativas en España realmente destacables, fundamentalmente desde algunas escuelas de música -enseñanza no reglada-, y que cada vez hay más conciencia de la necesidad de contribuir al estado del bienestar social, pero los mayores impedimentos para poner en marcha iniciativas innovadoras son la falta de metodologías específicas, la falta de formación de los docentes en materia social y comunitaria, y la inercia a mantenerse inmóvil ante la perspectiva incierta de trabajar en proyectos desconocidos con resultados 
también inciertos que demandan mucho trabajo, reflexión y otros modos de hacer a nivel pedagógico a los que no se está acostumbrados.

Ante esta situación de inmovilismo general, con unas pocas escuelas de música afrontando retos y abriendo caminos, se hace necesaria una reflexión sobre la razón de ser de las escuelas de música y analizar los modelos educativos que se han empleado tradicionalmente y otros modelos emergentes que puedan dar respuesta a las necesidades de la sociedad en la que estamos inmersos sin restar por ello rigor y efectividad a la formación musical que se imparte. También conviene aclarar conceptos que tradicionalmente no se han empleado en el ámbito educativo musical y que en este siglo $X X I$ van a tener una gran relevancia en el contexto de las escuelas de música. Términos como mediación social, intervención socioeducativa o proyecto socio-comunitario, necesitan ser abordados y tratados sin miedo o prejuicios. Es cierto que la implementación de proyectos musicales socioeducativos en forma de talleres concretos requiere de esfuerzo y conocimiento del contexto, pero la creatividad e imaginación musical que todo músico y docente ha desarrollado a lo largo de su historia vital permite abordar estos retos con herramientas musicales que sólo desde el conocimiento musical se pueden desarrollar. Esto, unido al trabajo en colaboración con educadores sociales, puede propiciar también una nueva manera de entender la educación musical y nuevos perfiles profesionales dentro del colectivo de músicos.

Este artículo tiene como objetivos principales: 1) la clarificación de conceptos y tipos de contextos en el ámbito socioeducativo y comunitario; 2) una reflexión sobre los modelos educativos musicales tradicionalmente empleados en la formación musical y la incorporación de otros nuevos que sustenten los proyectos educativos socio-comunitarios; y 3) una propuesta de procedimiento para la puesta en marcha de un taller socioeducativo en una escuela de música.

\section{ACLARANDO CONCEPTOS}

\section{¿Qué es la educación social?}

Es alrededor de los años sesenta y setenta del siglo XX, y gracias en gran parte a las obras de Edgar Fauré (1973) y Coombs (1971, 1985), que se define un nuevo concepto de educación como un proceso no exclusivo de la infancia, sino a lo largo de todas las etapas evolutivas del ser humano, y no solo en las instituciones escolares, sino en todos los espacios sociales. Tal y como describe Froufe $(1997,181)$ : "La educación como proceso permanente se integra en dos categorías axiales: eje horizontal (espacios: familia, escuela, comunidad, trabajo); eje vertical (desde el nacimiento hasta la muerte)".

La educación social es objeto de estudio de la Pedagogía Social y los pedagogos como Froufe (1997) y Quintana (1988) defienden su existencia ya que la persona es un ser social y la educación es un proceso relacional que tiene lugar dentro de un grupo humano, dentro de una sociedad. Los continuos desajustes sociales que tienen lugar en nuestro entorno y la rapidez de los mismos han llevado a entender la Pedagogía Social y, por ende, la educación social, desde una perspectiva intervencionista, esto es, focalizando su acción en las realidades sociales desequilibradoras. Si la sociedad es cambiante y variada en sus contextos, también lo debe ser la educación social y sus intervenciones.

Existe un acuerdo mayoritario al considerar que la educación social tiene una incidencia directa en la Educación Social Especializada (inadaptación, marginación, exclusión social), en la Animación sociocultural (ocio y tiempo libre), en la Educación Permanente (principalmente de adultos) y la Formación laboral (en los colectivos en desempleo, reciclajes formativos para dar respuesta a los nuevos requisitos laborales, etc.).

\section{Los proyectos socioeducativos y comunitarios en el contexto actual}

La crisis económica de este comienzo de milenio, junto con factores como el tránsito a la sociedad postindustrial, el individualismo característico de las sociedades capitalistas, la emergencia de nuevas situaciones de riesgo social, la globalización, la transformación del 
mercado laboral, la integración de la mujer en el mismo, el envejecimiento de la población, los cambios en las estructuras de las familias y, más recientemente la pandemia sanitaria del nCovid 19, están conduciendo inexorablemente a una falta de atención a los nuevos retos de la llamada sociedad del bienestar por falta de recursos fundamentalmente. Los cambios sociales originan cambios en los modos de percibir la inclusión y exclusión social y los modelos de intervención quedan obsoletos. Eva Mayo (2017) alerta de la existencia de sociedades con trayectorias vitales más individualizadas y vínculos comunitarios débiles, donde la ciudadanía se enfrenta a nuevos riesgos sociales como son la fragilidad de la tercera edad, la conciliación de la vida laboral y familiar, la maternidad/paternidad individual, la baja cualificación profesional y una cobertura insuficiente de protección social, pública y privada, con servicios y prestaciones inadecuadas (pg.181).

Ante los nuevos retos sociales y comunitarios resulta preciso encontrar nuevas herramientas para hacer frente a nuevas vías de trabajo en lo social que desde la interdisciplinariedad pueda dar respuestas a los problemas de prevención y del riesgo de exclusión y la integración social a niveles locales, cercanos, en entornos culturales compartidos geográficamente. Creux (2012) se postula a favor de la intervención del arte como mediador en este trabajo social. Segado (2011) apuesta por un nuevo tipo de intervención social en la que el objetivo no sea inmediato sino a largo plazo y que se aspire a cambios duraderos en las personas. Se trata de superar la visión asistencialista, que atiende a las deficiencias específicamente, para atender a las necesidades enunciadas por las personas implicadas y que ellas mismas aprendan a manejar los conflictos y adquirir control sobre su propia vida. En este sentido, las últimas investigaciones en esta área, apuestan por el arte como herramienta de intervención.

El surgimiento de la arteterapia y el empleo de herramientas artísticas como mediadoras en la intervención social y comunitaria se han disparado en los últimos años, si bien, en el ámbito de la música no existe tanta literatura como, por ejemplo, en relación al empleo del dibujo, las imágenes, la pintura y otras artes plásticas.

\section{¿Qué es comunidad? El compromiso comunitario de las escuelas de música.}

Concepto complejo, versátil y polisémico cuyo concepto ha ido cambiando a lo largo del tiempo. Las últimas definiciones del término coinciden en considerar la comunidad como un ecosistema social en el que un grupo humano comparte área geográfica, relaciones e interacciones múltiples y en la que sus individuos llevan a cabo una serie de funciones. Este ecosistema les permite generar sentimientos de pertenencia al grupo y una identidad propia en su seno (Cieza, 2010). La comunidad tiene un grado de autonomía que permite considerarla como un ecosistema y presenta delimitaciones y características distintivas de otras comunidades: el territorio, la cantidad y tipo de población, las infraestructuras disponibles o potenciales, las necesidades, problemas, intereses y aspiraciones.

La comunidad es un auténtico espacio dialógico, dinámico, vivo, dentro de un contexto histórico que va evolucionando y en el que también tiene espacio la diversidad, el individualismo, al tiempo que una fuerte sensación de pertenencia a un colectivo. En opinión de Cieza (2010) es preciso que las comunidades recuperen su razón de ser y se conviertan en espacios de convivencia social donde el ciudadano recupere su protagonismo en el proceso de cambio y transformación de la realidad social.

La idea de que los centros escolares -entre ellos, los centros de educación musical- deben incardinarse en el tejido comunitario y responder a las necesidades sociales es de gran calado pedagógico y social y está asociada a la idea de la educación permanente y la educación a lo largo de la vida (Ortega, 2005). Otra idea asociada a la pedagogía social es que los centros de educación deben tener un compromiso prioritario con la formación integral de los estudiantes en cuanto a ciudadanos y que la instrucción recibida en estos centros no se reduzca a la mera repetición y distribución de conocimientos o a facilitar determinadas competencias básicas; los centros educativos, independientemente del área del conocimiento que impartan, han de comprometerse en la educación para la participación y transformación social, convirtiéndose así los propios cen- 
tros en auténticos agentes sociales en y para la comunidad.

Por último, los centros educativos no pueden permanecer aislados, encerrados en sí mismos y permanecer al margen de la realidad social y las necesidades del contexto, sino que deben abrirse a la comunidad local (Cieza, 2010).

\section{¿Qué es intervención socioeducativa?} Modelos de intervención/mediación. Antes de describir el concepto "intervención socioeducativa" hay que aclarar que es un término de uso controvertido en el ámbito educativo ya que hace referencia expresa a otros ámbitos no educativos, como la medicina, la economía y que trasladadas al ámbito educativo condicionan sus patrones de acción. Es por ello que existe una corriente de pedagogos que prefieren el término "mediación" al de "intervención", a pesar de la popularidad de este último término.

Existen dos grandes modelos que resumen las acciones de la intervención socioeducativa: el modelo tecnológico o reproductivo y el modelo crítico o reconstructivo. Según Sáez Carreras (1993), el enfoque de las universidades y centros superiores de educación sigue el modelo tecnológico, científico o positivista, convirtiendo estos espacios educativos en lo que él llama prescripción cognitiva. En este modelo hay una gran separación entre universidad y escuela ya que, en opinión de Sáez Carreras, unos sujetos diseñan el conocimiento (los científicos e investigadores) y otros lo aplican (los educadores), dando lugar a un vacío entre planificadores y ejecutores, entre teoría y práctica; "mientras los científicos elaboran sus teorías educativas en el laboratorio, otros intentan retraducir esas teorías en prácticas" (Sáez Carreras, 1993, pg. 92). La intervención socioeducativa desde este enfoque es un "proceso de acción sobre otros sujetos, produciéndose una intromisión y una alteración de su realidad ambiental y personal" (pg. 94).

El otro gran modelo, la intervención como práctica social crítica, es definida por House y Mathison (1983) como un acto fundamentalmente político: actos que no son neutros ni asépticos sino plagados de valores, intereses. Se trata de una concepción de la intervención de tipo dialógica caracterizada no por estar diseñada científica y tecnológicamente, sino que "es personal y socialmente significativa para los sujetos que la reciben" (Sáez Carreras, 1993, pg. 96). Los defensores del enfoque crítico de la intervención buscan en sus programas la emancipación social y personal de los individuos que, además, son protagonistas de su propio proceso de emancipación y autodeterminación (Bachman y Simonin, 1981). El gran modelo para esta concepción social y educativa es sin duda Freire, apostando por el compromiso, la participación y la democracia en educación.

\section{LA EDUCACIÓN ARTÍSTICA: MODE- LOS PARA LA MEDIACIÓN SOCIAL}

Barragán y Moreno $(2004,23)$ afirman que los modelos de aprendizaje y educación artística "pueden proporcionar ideas y propuestas tanto para los docentes en contextos formales como para los educadores y otros trabajadores de la intervención social". Eisner (1995), experto en educación artística, dibuió una primera aproximación a dos modelos generales de educación artística que justifican desde distintos ángulos la enseñanza del arte: por un lado la corriente esencialista y, por otro, la contextualista. Los seguidores de la corriente esencialista consideran que la experiencia artística que se desprende del aprendizaje artístico promueve en las personas una serie de emociones, sensibilidades y representaciones que no se generan en ningún otro tipo de área de conocimiento. Lo que se aprende a través de la experiencia artística, ya sea desde la creación o desde la interpretación, es único. Derivado de ello es que en este modelo el arte merece ser un ámbito de conocimiento en sí mismo, independientemente de sus posibilidades para contribuir al aprendizaje en otras áreas o con otras finalidades educativas.

En opinión de Barragán y Moreno (2004), el educador social está más ligado al modelo contextualista de la educación artística, ya que el objetivo es que mejore la situación individual y social de los individuos de un grupo, no que sea capaz de asimilar procedimientos artísticos para conseguir un producto final con un valor artístico.

Es habitual que en los centros de la red social se organicen talleres y actividades con contenido artístico. Estos talleres los desarrollan educadores sociales que no disponen de formación artística específica en su curriculum formativo. De todo ello se deriva que la calidad de di- 
chos talleres depende de la imaginación y/o especial intuición de los educadores, y de ahí se desprende el hecho de que estos talleres se programan sin un marco teórico adecuado ni metodologías artísticas específicas.

Lo anterior, pone de manifiesto la necesidad de aunar esfuerzos, conocimientos y metodologías específicas para llevar a cabo unos talleres en los que la actividad artística -en nuestro caso, música y danza- ha de actuar como mediadora. Parece lógico pensar que en los equipos de intervención artística haya profesionales de la rama del arte que se va a emplear como herramienta. No obstante, hay que poner énfasis en la idea de que la actividad artística es una herramienta educativa en estos contextos sociales; el objetivo principal no es que las personas a las que se dirigen los talleres aprendan a realizar un objeto artístico conforme los cánones académicos, sino que a través de estas actividades se trata de fomentar la autonomía de las personas, su identidad cultural y promover procesos de inclusión social. En este sentido, tampoco resulta suficiente la intervención del profesional del arte porque no se trata específicamente de educación artística, sino de mediación artística. Para esta mediación, por ejemplo los músicos, no disponemos de formación de tipo psicológica, pero sí tenemos las capacidades y conocimientos necesarios para imaginar y crear actividades relacionadas con la música en sus múltiples facetas. El profesional de la educación artística puede y debe complementar los equipos de trabajo que planifican y desarrollan talleres y actividades en los que se emplea la mediación/intervención del arte.

En opinión de Moreno (2010), "la actividad artística conecta al sujeto con su propia identidad individual y cultural; permite revisar su imaginario y acceder al universo simbólico" (pg. 2). Al igual que otros expertos en Pedagogía Social, Moreno defiende que la experiencia artística facilita al individuo el posicionarse críticamente ante la realidad, ante su "yo" y ante el mundo e imaginarse otras representaciones de ese yo y ese mundo en otros entornos y culturas. Este hecho propicia la idea de que ambos conceptos son revisables y cambiantes y dejan un espacio a la posibilidad del cambio y la transformación por el propio individuo. Se podría decir que la experiencia artística permite a las personas mirarse a sí mismas e imaginarse de otra forma y en otras circunstancias.

\section{Los modelos de educación musical en el siglo XXI}

Existen varios modelos de educación artística que reconocen la mayoría de los expertos. Un repaso a dichos modelos desde la perspectiva de la educación musical nos dibuja un escenario con modelos muy reconocibles, si bien en ocasiones se solapan entre sí ligeramente. La diferencia entre estos modelos es dónde se pone el énfasis del aprendizaje. Hay que decir que estos modelos no son excluyentes entre sí y que las escuelas de música pueden optar por varios modelos simultáneamente, como de hecho se ha venido haciendo hasta ahora con los centros educativos en los que se imparte enseñanza no reglada (modelo amateur) y enseñanza reglada (modelo academicista de conservatorio). Lo interesante en esta nueva propuesta de modelos educativos es poder combinar cualquiera de los tradicionales con otros emergentes (como el modelo de gamificación, o el modelo de educación para el ocio cultural), entre los que queremos destacar especialmente el modelo de intervención/mediación artística que pone en el punto de mira la acción educativa en colectivos no contemplados hasta ahora.

El Modelo Academicista: Recoge la tradición musical occidental y sus modos de hacer, interpretar, escribir y pensar la música desde el prisma de los grandes compositores de la música clásica, fundamentalmente. Este modelo de educación musical promueve la reproducción en términos académicos de todo ese corpus de saber y está orientado principalmente hacia el conocimiento del objeto de estudio. Su finalidad es dominar las técnicas y los procesos que llevan a la producción de una obra de arte, con sus distintas significaciones a lo largo de la historia del objeto de estudio, en este caso, la historia de la música occidental. Es el modelo de los conservatorios de música.

El Modelo expresionista: Trata la música como vehículo para la expresividad y la creatividad personal. Se desarrolla en paralelo a otras artes después de la II Guerra Mundial. Se trata de permitir que cada individuo se exprese con libertad a través de la música, aunque ésta no esté hecha con el rigor y las alturas de miras de una obra de arte. Aquí no se enseña a producir un objeto musical artístico, sino que se persigue que la persona saque su mundo interior. Este modelo forma parte de la enseñanza no formal, la no reglada que se imparte en es- 
cuelas de música o centros privados dirigidas fundamentalmente a los primeros contactos de los niños y niñas con la música, por ejemplo. O los talleres de música y expresión corporal que se ofrecen en academias y centros escolares como actividades extraescolares, etc. Aquí el tipo de música que se aborda es variada. De este modelo se pueden rescatar algunas ideas para el modelo que se propone de intervención/mediación social.

El Modelo Amateur: Muy frecuente en nuestro sistema educativo musical no reglado. Consecuencia directa de la democratización de las artes y el reclamo del acceso a las mismas de la clase media. Se trata de un modelo mixto en el que desde una concepción academicista de la educación, se forma a las personas en el lenguaje simbólico de la música con la finalidad de manejar un instrumento musical o la voz a unos niveles de destreza básicos, entendiendo que dichos niveles de destreza serán suficientes para el disfrute individual y colectivo de la música. Se persigue que los educandos disfruten de la música con un conocimiento básico de su lenguaje y principios técnicos. Este modelo se corresponde con la enseñanza no reglada de la música (Escuelas de música, en general) y parte de una idea, no compartida por todos, de que la música sólo se puede disfrutar si conoces su lenguaje y sabes tocar un instrumento mínimamente. Además, entre sus detractores, se apunta que este tipo de educación musical perpetúa en el tiempo un tipo de consumo elitista de un tipo concreto de música también elitista que favorece finalmente a la educación de tipo academicista, pero que no permite a toda la comunidad acceder a su comprensión y disfrute. El tipo de música es variado, si bien se mira de reojo como meta musical poder interpretar, siquiera a nivel facilitado, repertorio de tipo clásico. El objetivo es formar músicos amateurs. Este modelo también refleja el tipo de educación musical que tiene lugar en los colectivos locales amateurs como son los coros, las bandas $u$ orquestas comunitarias donde resulta indispensable una formación técnica para poder manipular un instrumento o la voz con un mínimo de rigor.

El modelo de Educación musical lúdica y para el ocio cultural: Se distingue del amateur en que no se trabaja instrumentalmente la música con la finalidad de obtener un producto musical de más o menos nivel artístico, sino que aspira al bienestar personal y a disponer de una mínima formación en torno a la música para su mejor apreciación, pero nunca manipulan-

Figura 1

Resumen de los modelos educativos musicales a comienzos del siglo XXI

\section{Los modelos de educación musical en el siglo XXI}

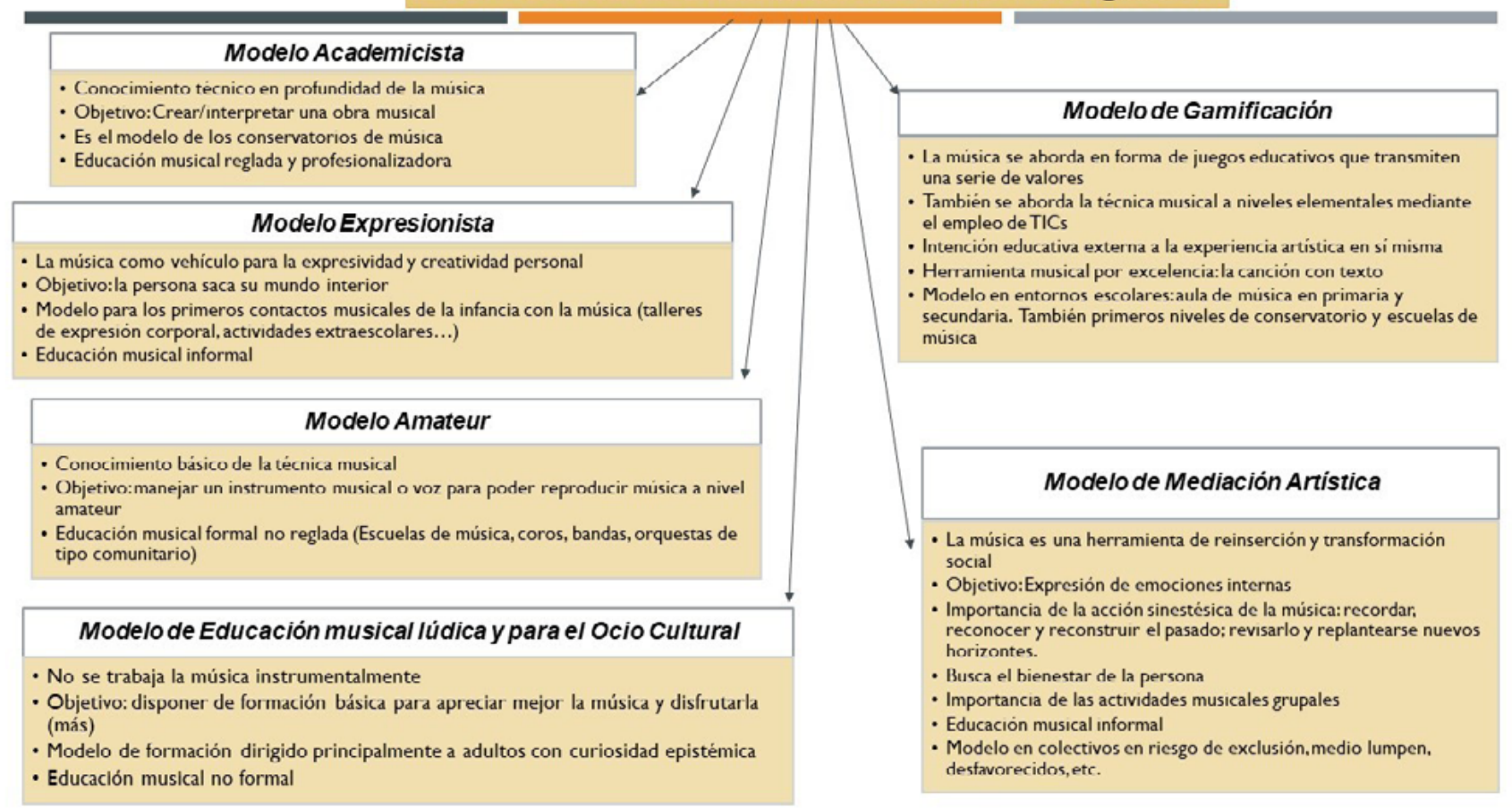


do el producto artístico o intentando emularlo. Este modelo es ampliamente empleado en las instituciones de formación para el ocio cultural, el ocio universitario y los consumidores suelen ser adultos que, generalmente, tienen acceso a las manifestaciones artísticas musicales más elitistas pero carecen de la formación para comprender la complejidad del arte musical, si bien lo intuyen y lo disfrutan. Este disfrute les lleva a la curiosidad epistémica de querer conocer más sobre la música: su historia, los estilos, compositores, géneros, etc.

El modelo de gamificación: emplea la música como material susceptible de tratarse en forma de juegos educativos en los que el objeto educativo puede ser la propia música o, más a menudo, a través de ella educar en otros aspectos al ser humano. Este modelo en el que las acciones educativas se centran en el juego son especialmente útiles en el colectivo infantil en entornos escolares en los que la música, generalmente canciones -música con texto-, sirven para vehicular indirectamente conceptos, valores e ideas transversales en la educación. En este modelo no se educa en música, por mucho que estas actividades se lleven a cabo en el espacio curricular de música. Existe una intención educativa externa a la experiencia artística en la que se emplea la canción fundamentalmente por su colateralidad discursiva con el valor o concepto en el que se quiere educar. Es por ello que este modelo emplea como material de trabajo las canciones populares, canciones reivindicativas o canciones cuyo elemento central (ya sea en el estribillo, o en el trasfondo) sea su relación textual con un tópico determinado. Se disfruta la música desde un plano secundario ya que en primer plano educativo se halla el mensaje discursivo del texto. Tampoco se trabajan estructuras o elementos musicales. Los tipos de juegos son muy diversos y abarcan acciones como cambiar el texto originario de una canción muy conocida, "representar" gestualmente el texto de la canción de manera colectiva, poner música a un texto de manera individual y en grupo, y más recientemente, con la incorporación de las TICs también para interactuar en el aula y manejar la música digitalmente con imágenes, fotografías, etc. En este modelo de gamificación entrarían asimismo las actividades que en forma de juegos se realizan en los primeros estadios educativos de sensibilización a la música en niños y niñas en etapa pre-escolar.
La Mediación Artística: Se trata de un modelo que pone en valor la Música como una herramienta; el objetivo que se persigue es la experiencia artística y lo que a través de ella se puede cambiar o transformar, independientemente de los resultados sonoros concretos. No importa la calidad técnica o artística del producto musical que se deriva de la mediación musical; el objetivo no es formar músicos. El taller de música pasa a ser una herramienta de reinserción y transformación social. Moreno (2010) atribuye a la Mediación Artística algunos conceptos ampliamente manejados desde la pedagogía, la psicología o el trabajo social (pg 5): a) desarrollo integral de la persona b) Elaboración simbólica y superación de conflictos c) toma de conciencia de la situación actual e inicio de un proceso de transformación y reinserción.

La arteterapia y la musicoterapia no son tipos de educación artística, sino terapias a través del arte. El interés se desplaza de la producción final al proceso (Moreno, 2010).

\section{Beneficios de la mediación artística musical en ámbitos socioeducativos.} Barragán y Moreno $(2004,31)$ han descrito los beneficios de la experiencia artística en colectivos sociales con dificultades, que nosotros hemos hecho extensivos después de matizarlos, a la experiencia artística musical, elaborando el siguiente decálogo:

1. La música proporciona oportunidades para acercarse al pasado y revivirlo simbólicamente

2. Participar en actividades musicales colectivas permite al individuo sentir una identidad de pertenencia al grupo y sentirse a salvo y protegido, importante y necesario, aceptado como uno más en un entorno sin peligros.

3. Los individuos a través de la acción sinestésica de la música pueden recordar, reconocer y reconstruir su pasado desde una perspectiva actual, asimilar simbólicamente los acontecimientos y experiencias vividas y revisar el significado para replanteárselo.

4. A través de la producción sonora, el individuo puede expresar sus emociones internas difícilmente comunicables de manera 
discursiva, sin necesidad de hacerlas explícitas.

5. La experiencia grupal en actividades colectivas facilita la colaboración con los otros, la negociación y el intercambio de habilidades. Propicia la inter-relación en un contexto sano con otros individuos y propicia el aprender a escuchar, a ponerse en el lugar del otro y a aceptar e integrar lo que es diferente.

6. La música puede vehicular experiencias sensibles muy diversas en función del tipo de música empleada en cada actividad (sentimiento festivo, reivindicativo, melancólico, amoroso, de fraternidad, de añoranza, de libertad, etc.)

7. A través de la música se puede propiciar un ambiente lúdico, de disfrute, sin otro objetivo que el de relajar tensiones y procurar un estado de bienestar personal y colectivo, más allá de una intención terapéutica.

8. Se estimula la creatividad y la imaginación, la espontaneidad y la inventiva, lo que puede hacer aflorar la capacidad de reinventarse e imaginarse a sí mismos en otro entorno y con otra imagen, es decir, reconstruyendo su propia vida.

9. Aumento del auto-concepto, de la autonomía y de la motivación personal.

10. Propicia la reflexión, el insight, la toma de conciencia de uno mismo.

\section{LA PLANIFICACIÓN DE PROYECTOS MUSICALES SOCIOEDUCATIVOS.}

Existen diferencias metodológicas a la hora de abordar la planificación de los proyectos socioeducativos en el ámbito formal y no formal y estas diferentes perspectivas se sustancian en distintos modos de abordar la realidad y afectan a sus resultados. Así, en la planificación de tipo tradicional la orientación del trabajo es de tipo autoritario, jerarquizado, de tipo "escritorio", originando diseños fundamentalmente unilaterales, bastante alejados de lo deseable en materia socioeducativa. Por otro lado, la planificación estratégica de tipo participativa es más acorde con el espíritu y las necesidades de la pedagogía social, ya que permite a los distintos agentes del proyecto una gestión horizontal en la que participan también los be- neficiarios y en el que se tienen en cuenta específicamente las características sociales, económicas, culturales y geográficas del grupo al que va destinado.

Luján Ferrer (2010) advierte que para efectuar una ruptura epistemológica con el paradigma administrativo tradicional es indispensable fomentar el sentido de pertenencia de los grupos humanos, habilitar espacios para que la comunicación sea fluida y permita que afloren acciones tendientes a juzgar, interpretar, escuchar, acceder, resolver, definir y plantear las ideas y las acciones educativas no formales.

La planificación participativa de estos proyectos a nivel local tiene el propósito de generar cambios sostenidos y pertinentes, son los beneficiarios quienes reclaman las actuaciones, los tiempos, describen sus necesidades sociales, culturales y económicas y van fijando el proceso de desarrollo del mismo. Los profesionales en educación están al cargo de todos los detalles técnicos: objetivos, temáticas, instrumentos, actividades, metodologías, evaluación y seguimiento, entre otras cuestiones.

Hay que advertir que los procesos de planificación deben ser abiertos y flexibles para acomodarse y reconducirse en cada momento en función de las necesidades que se vayan generando y los resultados que se vayan observando.

\section{Los diseños curriculares en los pro- yectos socioeducativos. Metodología dialógica}

El enfoque pedagógico que subyace en los proyectos socioeducativos tienen un marcado carácter dialógico, de transformación continua en función de los acontecimientos, de adaptación a los cambios que van sucediendo en cualquiera de las partes y actores del proyecto. Un mismo proyecto puede no ser aplicable a otro colectivo humano en un entorno cultural, social, económico o geográfico distinto. Algunas características propias de estos diseños Curriculares/educativos y principios ideológicos son:

- Aprendizaje dialógico

- Diálogo igualitario entre todos los actores

- Las personas somos seres en continua 
transformación (Freire, 1996). El aprendizaje dialógico permite el cambio en las personas y en el entorno.

- La creación de un sentido de identidad propia, de pertenencia a una comunidad, un colectivo, un sistema humano.

- La solidaridad

- Concede gran importancia al aprendizaje intergeneracional y al aprendizaje entre pares.

Todas las dinámicas participativas de los proyectos socioeducativos promueven el diálogo entre todos los participantes en condiciones de igualdad. En este contexto educativo, y de acuerdo a Freire (1996), el educador en estos proyectos debe ser un educador democrático, que no opera trasmitiendo conocimiento, sino

\begin{tabular}{|c|}
\hline $\begin{array}{l}\text { Ámbitos de intervención } \\
\text { socioeducativa por mediación de la música }\end{array}$ \\
\hline Protección y Reforma de menores \\
\hline Centros de acogida de menores \\
\hline Instituciones penitenciarias \\
\hline $\begin{array}{l}\text { Tercera edad: residencias, apoyo social en situaciones } \\
\text { de abandono }\end{array}$ \\
\hline
\end{tabular}

Mujeres maltratadas

Madres adolescentes

Drogodependencias: granjas, centros de tratamiento

Centros de inmigración, migración, interculturalidad

Pobreza, exclusión social mológicamente curiosos, se apropien del significado profundo del objeto de aprendizaje.

\section{Ámbitos de intervención}

\section{socioeducativa y socio-comunitaria}

Son muchos los ámbitos posibles de intervención socioeducativa y comunitaria en los que tienen cabida proyectos musicales. A los ya conocidos se van sumando paulatinamente contextos nuevos susceptibles de intervención generados por nuevos lumpen sociales resultado de la crisis económica mundial y de las consecuencias de una globalización económi$\mathrm{ca}$, laboral y cultural que ha agravado y matizado las necesidades de los diferentes estratos sociales a nivel mundial. En España, por ejemplo, sin pretender hacer un listado exhaustivo y cerrado, se pueden identificar distintos ámbitos de actuación a nivel socioeducativo y socio-comunitario (Tabla 1).

\section{Tabla 1}

Ejemplos de ámbitos de intervención socioeducativa y ámbitos de educación musical socio-comunitaria

\section{Fuente: elaboración propia}

\section{Ámbitos de educación musical con impacto} socio-comunitario

Escuelas de Adultos

Clubs de ocio cultural y tiempo libre (infantil, adolescencia, adultos, ancianos)

Colonias musicales y campamentos de verano

ONGs (acompañamiento a la actividad y/o a la visualización de la labor de una ONG)

Asociaciones musicales amateurs con actividad periódica (bandas, coros, orquestas, agrupaciones instrumentales, etc.)

Actividades musicales comunitarias específicas en festividades señaladas y celebraciones tradicionales

Conciertos benéficos a favor de proyectos comunitarios

Audiciones públicas de los estudiantes de música de los centros educativos (impacto en las familias, amigos, vecinos, etc.)

Centros hospitalarios, especialmente de larga estancia

Discapacitados físicos y psíquicos 


\title{
¿QUÉ SE PUEDE HACER DESDE LA ESCUELA DE MÚSICA? MODALIDADES DE PARTICIPACIÓN COMUNITARIA Y SOCIAL.
}

Figura 2

\author{
Modalidades de participación comunitario y social en las Escuelas de Música \\ Fuente: elaboración propia
}

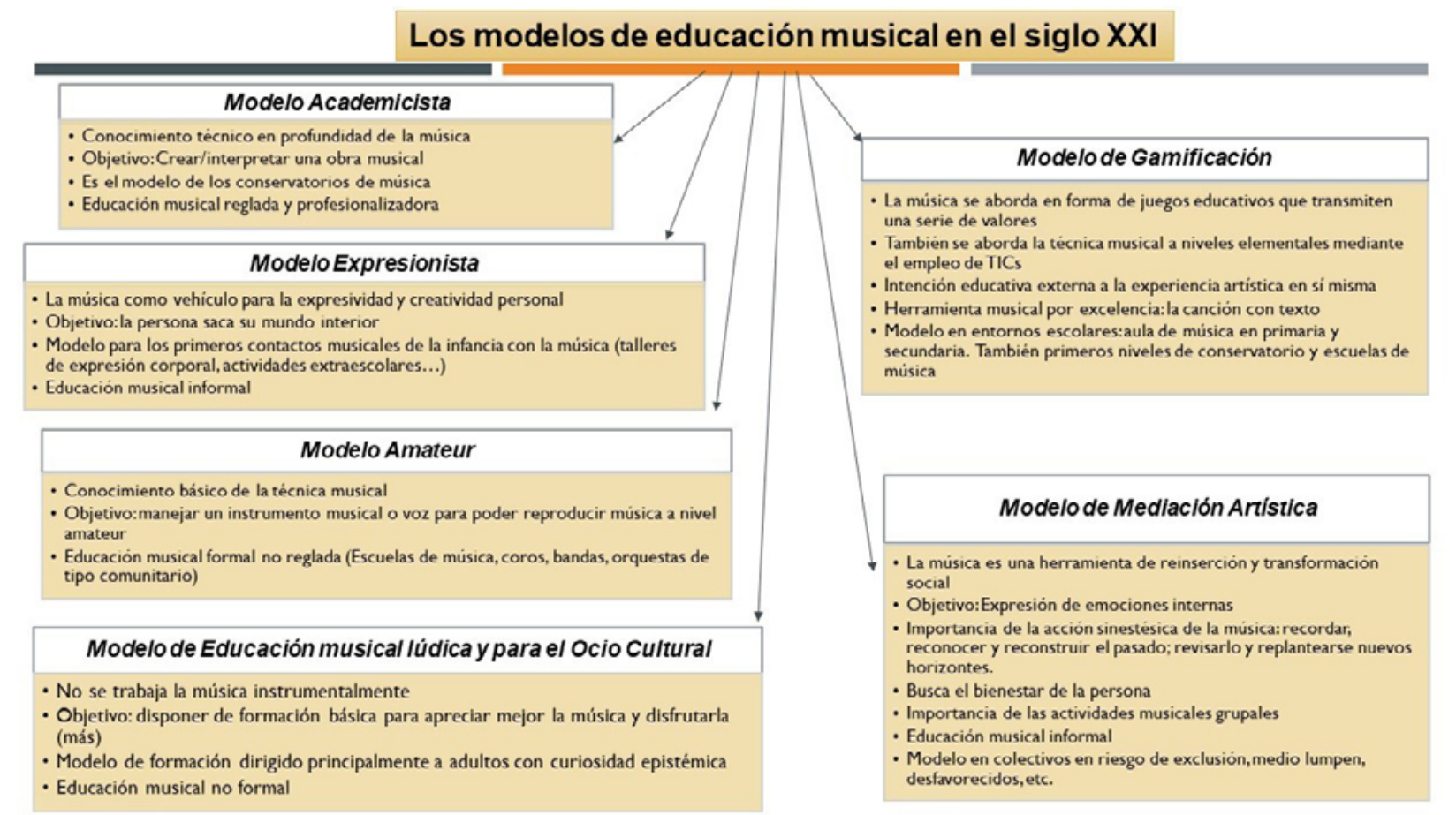

\section{Desde el alumnado (y sus familias)}

a) Implicación y participación en proyectos comunitarios ya existentes, colaborando con otras instituciones, asociaciones culturales y educativas de la comunidad. Por ejemplo: Semanas o días conmemorativos (la paz, el medio ambiente, etc.), festividades locales, actos reivindicativos sociales, actividades artísticas en instituciones comunitarias o en colectivos en riesgo de exclusión social, etc.

b) Planificación y desarrollo de proyectos comunitarios propios. Los estudiantes inician de este modo una actividad que contribuya a la dinamización de la comunidad (difusión musical, animación sociocultural, espacios lúdicos) en función de las necesidades detectadas en el entorno local.

\section{Tipos de proyectos para desarrollar por el alumnado.}

Pueden ser proyectos sociales: apoyo a colectivos en riesgo de exclusión, marginación o minorías culturales, discapacitados, enfermos crónicos, etc. dentro de estos proyectos sociales estarían también las acciones y actividades encaminadas a hacer visibles causas solidarias y humanitarias, así como las encaminadas a promover una mayor relación intergeneracional e interpersonal entre diferentes grupos humanos del colectivo (con la tercera edad, con inmigrantes, etc.)

Los proyectos formativos hacen referencia a la participación de los estudiantes en actividades musicales o artísticas de carácter divulgativo, acercando la música de todo tipo de una manera didáctica a distintos colectivos, buscando 
el disfrute y un acercamiento a la música desde diversas perspectivas, según los intereses particulares del grupo al que van destinadas.

Los proyectos culturales emplean los recitales, conciertos de música y danza, los coros, bandas y orquestas de los centros de música, solos - combinados con otras actividades artísticas (teatro, poesía, iluminación, etc.), para divulgar la música no sólo clásica, sino, y muy especialmente la música tradicional y del folklore. También dentro de los proyectos culturales se pueden diseñar actividades de recuperación y conservación del folklore, tradiciones y cultura popular, actividades de investigación etnográfica, y de conservación del patrimonio musical popular.

Los proyectos lúdicos-recreativos abarcan actividades como la organización de concursos y certámenes (de bandas, de coros, de grupos de instrumentos autóctonos, etc.), animación infantil, juvenil y de personas mayores (música para bailar, música de películas, música de canciones infantiles, música pop-rock más actual, etc.), etc.

Las metodologías de intervención/mediación con estudiantes de música son fundamentalmente la animación educativa y el aprendizaje-servicio (prácticas de aprendizaje que al mismo tiempo suponen un servicio al colectivo comunitario al que van dirigidas).

\section{Desde el profesorado}

El profesorado de las escuelas de música podría diseñar actividades a nivel individual y colectivo destinadas a nuevos colectivos de usuarios con una finalidad distinta de la que se lleva a cabo en los modelos de Educación Musical Amateur y Academicista. Se pueden pensar en otros modelos educativos más orientados a la Mediación musical para colectivos sociales del entorno en riesgo de exclusión o con necesidades que se pueden abordar a través de la música.

Este nuevo ecosistema educativo se mueve en un espacio-tiempo diverso y con unos sujetos educandos que precisan de los conocimientos de los docentes de música para, juntamente con otros profesionales de la educación social, sembrar semillas para el cambio y la transformación social de nuestro entorno. Afrontar estos nuevos espacios educativos exige repensar nuestra identidad como profesores de músi- $c a$, dotando a nuestra labor de un significado más amplio y diversificado, más acorde con el compromiso que debemos a la sociedad en la que nos imbricamos.

Es seguro que la formación del profesorado comprometido con el bienestar de todos los individuos que conforman una comunidad ha de verse ampliada en algunos aspectos sociales que no se han abordado hasta ahora y que los diseños curriculares de las instituciones superiores de educación encargadas de formar al profesorado de música habrán de ser revisados, complementados o modificados a la luz de las nuevas necesidades del perfil del profesor de música del siglo XXI, profesorado comprometido socialmente.

Se precisan iniciativas desde el profesorado de todos los centros educativos musicales a todos los niveles porque no existe suficiente experiencia aún en la implementación de talleres y actividades musicales con vocación de mediación en los conflictos y desigualdades sociales. Desde la universidad es importantísima la investigación sobre la práctica educativa en estos otros entornos y contextos para avanzar en el conocimiento de sus beneficios y los modos de conducirse en este nuevo ecosistema social en el que deseamos mediar, colaborar, intervenir... llámese como se prefiera. Por eso, experiencias piloto con diversos materiales musicales, distintos procedimientos y herramientas creativas serían deseables para explorar este modelo de Educación musical para la mediación social.

\section{Lugar de realización de las activida- des}

Las actividades que se desarrollen pueden tener lugar dentro de la propia institución educativa, en este caso, las aulas de la escuela de música, o bien que sea la escuela la que se acerque a otros espacios comunitarios abiertos o cerrados (espacios urbanos $u$ otros espacios disponibles en las propias asociaciones que demandan la mediación). La ventaja de que los colectivos se desplacen al centro musical es la de disponer de toda la infraestructura necesaria para llevar a cabo un taller de música y el valor añadido de dar una pátina de normalidad al colectivo que se convierte en un usuario más de instalaciones comunitarias. No obstante, se debe evaluar la conveniencia de estas visitas de otros colectivos al centro en función del horario o las necesidades especiales del propio colectivo. 


\section{Infraestructuras e instituciones colaboradoras}

Es impensable llevar a cabo iniciativas socioeducativas y comunitarias sin el apoyo de las asociaciones de colectivos a los que se quiere llegar con la mediación. La colaboración entre instituciones públicas, privadas, asociaciones y administración es absolutamente necesaria. Además, en todo proyecto comunitario es fundamental que sea la propia comunidad la que fije las necesidades y solicite las intervenciones que se precisan más urgentemente.

\section{Diagnóstico de necesidades}

El diagnóstico de las necesidades precisa estar en contacto con los centros y asociaciones comunitarios, con los educadores sociales de la administración y con los trabajadores sociales que conocen a nivel local las realidades más acuciantes. Las escuelas de música pueden ofertar su participación en proyectos socioeducativos, pero el colectivo de destino es preciso consensuarlo con los agentes sociales para hacer frente a las necesidades reales y actuales en cada momento histórico local.

\section{Financiación de proyectos}

Las escuelas de música podrían pasar a formar parte del grupo de empresas sociales sin ánimo de lucro, con una gobernanza participativa en el diseño y realización de cada proyecto individual, con la posibilidad de recibir financiación europea para estas actividades socioeducativas y/o ayudas privadas, patrocinios, además del soporte de la administración para asuntos sociales. Estas acciones se enmarcan dentro de lo que se ha dado en llamar emprendimiento social que lleva a las empresas de una concepción tradicional de la producción de bienes privativos a otra en la que conviven los beneficios privados con los beneficios sociales y la mejora, mediante la transformación y cambio, de la sociedad.

\section{Formación del profesorado de música en proyectos socioeducativos}

Sería preciso diseñar cursos de formación, cursos de capacitación, de postgrado o de especialización para habilitar al profesorado de música de todos los niveles como mediador social en proyectos musicales comunitarios y socioeducativos. Esta especialización permitiría, además, abrir nuevas vías de inserción laboral en el mercado de trabajo para los profesionales de la música.

\section{PLANIFICACIÓN DE UN TALLER MUSICAL SOCIOEDUCATIVO}

La planificación de los talleres socioeducativos desde la Escuela de Música es una tarea colectiva que implica a todo el claustro de profesores, estudiantes, familias y todo el personal de administración y servicios del centro. Cuando el taller se va a realizar dentro del recinto de la escuela de música es necesario prever espacios, horarios e infraestructuras necesarias (recursos para el aula). La designación del profesorado que se encargará de estos talleres es decisión final de la dirección de los centros en función de las necesidades y los perfiles más adecuados dentro del cuerpo docente. Conviene siempre disponer de un grupo de trabajo que dentro de la escuela se encargue de coordinar los talleres, tanto a nivel interno (planificación didáctica, recursos pedagógicos, diseño de actividades, etc.) con todo el profesorado involucrado en los talleres, como a nivel externo con las asociaciones destinatarias de los talleres, administración de asuntos sociales (ayuntamiento, diputaciones, etc.), y el educador o educadora social que colabora en el proyecto y que generalmente es designada por el departamento de asuntos sociales de la administración pertinente, o bien la persona que trabaja habitualmente con el colectivo de destino (ver Tabla 2). El impacto de los costes de cada taller (remuneración de los docentes, material empleado, desplazamientos, en su caso) ha de ser evaluado conjuntamente entre la dirección de la escuela de música y los interlocutores a los que va dirigida la actividad (administración correspondiente y asociación/ colectivo implicado).

Tabla 2

Pasos para la planificación de una mediación/intervención socioeducativa a través de la música desde las escuelas de música Fuente: Luján Ferrer, 201 0, pg. 108

- Definir la naturaleza del proyecto: ¿̇Qué se quiere hacer?

- Definir los motivos que apoyan la planificación del proyecto: ¿̇Por qué se va a hacer? 
- Determinar los objetivos: ¿̇Para qué se hace?

- Determinar las metas o logros: ¿̇Qué nivel se va a alcanzar?

- Definir el lugar o lugares en los que se desarrollará la acción: ¿̇ónde se va a hacer?

- Definir las actividades, metodologías, y demás acciones pedagógicas mediante las cuales se llevará a cabo el programa de educación no formal: ¿Cómo se va a hacer?

- Definir el tiempo y la duración de la actividad: ¿Cuándo se va a hacer?

- Identificar al personal que se requiere para la actividad: ¿¿Quiénes realizarán la actividad?

- Especificar los recursos materiales o financieros necesarios para aplicar al programa: ¿̇Con qué se hará la actividad?

Estructura y desarrollo de los talleres Los talleres se estructuran en función del colectivo humano al que va dirigido. El contenido y desarrollo de cada proyecto debe estar contextualizado a las posibilidades y necesidades de las personas que lo van a recibir. Cuando se trata de colectivos con minusvalías o discapacidades físicas o psíquicas, el diseño de la actividad difiere sustancialmente del modelo que vamos a presentar a continuación de modo genérico. Cuando el colectivo es infantil, por ejemplo, existen estrategias pedagógicas diferentes a la hora de acercarse a los sujetos que, por su edad, no es previsible que puedan ofrecer un feedback de la actividad en los mismos términos que lo haría un adulto. Quede claro, por tanto, que los talleres han de ser diseñados específicamente para cada tipo de colectivo y que no son intercambiables entre sí. No obstante, sí que existe una estructura general en los talleres destinados a colectivos en riesgo de exclusión social y lumpen (drogadicción, pobreza, delincuencia -en todas las edades-, instituciones penitenciarias, prostitución, etc.).

\section{Talleres para colectivos en riesgo de exclusión social y medio lumpen}

Generalmente se realizan en dos partes: la primera de producción de la actividad y la segunda de reflexión abierta y debate dialógico. Esta segunda parte de reflexión es importante para que se objetiven aspectos simbólicos que han ido emergiendo durante la práctica del taller. Si únicamente se realiza la actividad, el taller se transforma en algo lúdico, que aunque no es despreciable en algunas intervenciones en ciertos colectivos, no contribuyen a la exteriorización simbólica de los problemas subyacentes sobre los que queremos operar.

Para atender estas dos partes, el tiempo de realización del taller debe ser suficiente, se aconseja no menos de 1 hora para que el tiempo de contacto grupal también conduzca a la sensación de pertenencia a un colectivo con los beneficios que se derivan de esta identidad grupal a la hora de comunicar y expresarse en libertad y respeto. Es importante que en el taller se cree un espacio "seguro" donde los participantes puedan expresarse sin ser censurados ni cuestionados. El docente/educador no debe juzgar los resultados musicales desde un concepto academicista, ni ningún otro. La música es el medio, no el objetivo final. Se recomienda que las únicas normas para los talleres sean la no agresión a las personas y a las cosas. Incluso la no actividad es una forma de expresión que puede tratarse después en la parte de reflexión.

Aunque puede parecer que el educador/docente de música ha de tener conocimientos profundos de psicología, en realidad no es necesario realizar diagnósticos, ni interpretar lo que sucede en el taller a la luz de distintas teorías psicopedagógicas. El docente posibilita mediante las actividades que la música de paso a reflexiones de los propios protagonistas del taller. El docente observa pero no interpreta lo que se dice y hace. Solo incita a la reflexión y a que cada uno haga una interpretación propia de lo acontecido, lo vivido, lo sentido, etc. También revisa si la actividad programada es recibida positivamente o no por el colectivo para poder ajustar dialógicamente la misma a las necesidades expresadas por el grupo en ese espacio de reflexión abierta. En la Tabla 3 se presentan algunas preguntas que pueden ayudar al docente a guiar la reflexión después de la actividad. Hay que recordar que la música es el medio no el fin del taller. 


\section{Tabla 3}

Algunas preguntas para la reflexión después de la actividad

Fuente: elaboración propia

\section{Algunas preguntas para la reflexión} después de la actividad

- ¿Cómo se ha enfrentado cada uno a la tarea?

- ¿̇Cómo han actuado en el desarrollo de la actividad?

- ¿QQué recuerdos les trae la música que se ha tratado en la actividad?

- ¿̇Con qué técnica se expresan y por qué? (ritmo, melodía, respuestas, texto empleado...) No olvidemos que cada elemento musical propicia más unos aspectos afectivos o emocionales que otros.

- ¿̇Con qué dificultades se encontraron?, y ¿̇ómo se enfrentaron a las dificultades? ¿̇cómo las resolvieron?

- ¿Qué estrategias están utilizando para resolver los problemas? Solos, solicitan ayuda, consejo...

- ¿̇Cómo se adaptan a las diferentes circunstancias y acontecimientos que suceden durante el transcurso del taller?

- ¿̇ómo es la relación con los demás?, ¿qué rol desempeñan en las actividades grupales?

- ¿̇Qué valores tienen?, ¿̇cómo actúan los valores individuales en la actividad grupal y qué relación puede haber entre lo que sucede en el taller y lo que ocurre fuera, en la vida?

- ¿̇Qué opinan del taller? ¿QQué les gustaría añadir o quitar?

- ¿̇Han tenido experiencias previas con la música? ¿Cuándo, dónde, cómo?

- ¿̇ué sentimientos han aflorado durante el taller y con la música?

- ¿̇Desean continuar realizando el taller?
En estos talleres, la planificación de la actividad y su desarrollo se realiza en colaboración con el educador social, con un psicólogo o con los profesionales con los que cuente la institución a la que pertenece el colectivo. Digamos que el trabajo multidisciplinar permite aunar criterios y fundamentar el taller desde muchas perspectivas distintas. Sin embargo, resulta muy recomendable, como ya se ha visto, la formación básica en aspectos de psicología y pedagogía social.

\section{CONCLUSIONES}

Todas las instituciones educativas musicales pueden sumarse al compromiso por el bienestar, el cambio y la transformación social no sólo como valor transversal de los diseños curriculares, sino de forma activa, proyectando talleres, cursos y otros formatos de experiencias educativas (seminarios, prácticas, etc.) que incorporen el modelo educativo de Mediación Artística en su proyecto educativo. Aunque existen ejemplos de iniciativas innovadoras a la hora de abordar el compromiso socio-comunitario de algunas escuelas de música, este espíritu no ha permeado aún en el entramado de las instituciones educativas musicales en España y para promover el cambio se hace necesaria una profunda reflexión en torno a los modos de hacer y de entender la música y la educación en todos los ámbitos de la formación musical.

Las escuelas de música, por su propia naturaleza (enseñanza no reglada, multiplicidad de centros y distribuidos por toda la geografía, dando servicio a una comunidad cercana), pueden dar cabida a modelos educativos emergentes que se combinen con el tradicional modelo amateur predominante en sus aulas para dar un mayor servicio a la comunidad en la que se imbrican y hacerlo, además, a grupos humanos que no han tenido acceso a la educación musical y sus beneficios por distintas causas (educación musical de tipo lúdico y para el ocio cultural, talleres de adultos, tercera edad, creación y/o asesoramiento de proyectos musicales comunitarios, música para edades tempranas, colaboración con la administración en el calendario de festejos donde interviene la música en todas sus facetas y para todos ...) así como la intervención en ámbitos lumpen (pobreza, riesgo de exclusión social, maltrato, instituciones penitenciarias, migración, etc.) mediante la implementación del modelo educativo de mediación artística con 
una clara vocación de servicio y compromiso social para el cambio y el bienestar de todas las personas.

Las posibles inercias debidas a los modelos tradicionales de educación musical se pueden vencer con imaginación y creatividad y los proyectos han de responder a demandas reales de los colectivos sociales del entorno. Las escuelas de música pueden ver ampliada así su red de usuarios con individuos con diferentes intereses a los tradicionales, a los que la formación musical impartida por los docentes debe hacer frente con metodologías adecuadas y distintas de las experimentadas en el pasado en muchos casos. No obstante, no se deben temer estos nuevos retos porque el profesorado y las directivas de las escuelas de música no están solos en esta tarea: los proyectos socioeducativos de mediación a través de la música han de ser diseñados y desarrollados en equipos de trabajo junto con educadores sociales, psicólogos y las instituciones demandantes de estas actividades, además de la administración local para asuntos sociales.

Hay que poner de relieve que para llevar adelante proyectos socioeducativos y comunitarios se ve necesario incluir en la formación de los profesores de música las bases sociales y comunitarias imprescindibles para poder manejarse con soltura y sin prejuicios en el ámbito socioeducativo. No es necesario ser educadores sociales, ni psicólogos, pero si es preciso entender el contexto educativo para poder diseñar las actividades musicales poniendo el foco en el proceso, no en el producto final, que es el modo en que tradicionalmente se ha venido evaluando el proceso educativo musical. El objetivo final difiere totalmente en el modelo de medicación artística. Ser consciente de ello obliga necesariamente a un cambio de paradigma a la hora de entender la posición del educador, del educando y de los procesos educativos en el ámbito de la música.

\section{REFERENCIAS}

Bachman, C. y Simonin, J. (1981). Changer du cotidien. Edit. Etudes Vivantes, París.

Barragán, José María y Moreno, Ascensión (2004). Experiencia artística y producción cultural, ámbitos para la intervención socioeducativa. Educación Social, 28,19 39. En https://www.researchgate.net/
publication/42596813_La_mediacion_artistica un modelo de educacion artistica para_Ta_intervención_social_a_trāves_del arte

Cieza, J. A. (2010). El compromiso y la participación comunitaria de los centros escolares. Un nuevo espacio-tiempo de 
intervención socioeducativa. Pedagogía Social. Revista Interuniversitaria, 17, 123136. En http://www.redalyc.org/articulo. oa? id $=135013577010$

Creux, G. (2012). Art and social work. Towards a sociological analysis. Bordeaux.

Coombs, Ph. H. (1971/1985). La crisis mundial de la educación. Barcelona, Península, - La crisis mundial de la educación. Perspectivas actuales. Madrid, Santillana.

Eisner, E. W. (1995). Educar la visión artística. Barcelona: Paidós.

Fauré, E. (1973). Estrategias de la innovación. Perspectivas: revista trimestral de educación, II (1), 5-10. Oficina internacional de Educación de la UNESCO.

Freire, P. (1996). Política y Educación. Siglo XXI Editores. México

Froufe Quintas, Sindo. (1997). Los ámbitos de intervención en la educación social. Aula, 9, 179-200. https://gredos. usal.es/bitstream/handle/10366/69276/ Los ambitos de intervencion en la edu-

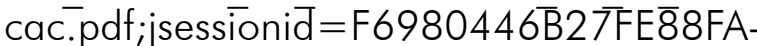
$4159664895 \mathrm{CA} 76 \mathrm{E}$ ? sequence $=1$

House, E. y Mathison, S. (1983). Educational intervention. En Seidman edit. Handbook of Social intervention, Sage publications, Beverly Hills.

Luján Ferrer, M. (2010). La administración de la educación no formal aplicada a las organizaciones sociales: Aproximaciones teórico-prácticas. Revista de Educación, 34 (1), 101-118. http://www.redalyc.org/ pdf/440/44013961006.pdf

Mayo, E. (2017). El arteterapia en el contexto de los Servicios Sociales de Base: el taller de arteterapia como espacio de observación para la intervención primaria. Arteterapia. Papeles de arteterapia y educación para inclusión social ISSN:1698-7454 http://dx. doi.org/10.5209/ARTE.57569

Moreno, A. (2010). La mediación artística: un modelo de educación artística para la intervención social a través del arte. Revista Iberoamericana de Educación, 52(2). https://dialnet.unirioja.es/servlet/articulo?codigo $=3170044$
Quintana, J. M. (1988). Pedagogía social. Madrid, Dikynson.

Ortega, R. (2005). Intervención con los alumnos. En IX Encuentro Internacional Violencia y Escuela. Valencia: Centro Reina Sofía para el estudio de la violencia.

Sáez Carreras, J. (1993). La intervención socioeducativa: entre el mito y la realidad. Pedagogía social: revista interuniversitaria, 8, 89-106. En https://dialnet.unirioja.es/ servlet/autor? codigo $=134514$

Segado, S. (2011). Nuevas tendencias en el trabajo social con familias. Una propuesta para la práctica desde el empowerment. Madrid: Trotta. 